\title{
Correction to: Diagnostic performance of semi-quantitative and quantitative stress CMR perfusion analysis: a meta-analysis
}

Journal of Cardiovascular Magnetic Resonance

\section{Correction}

In the original publication of this article there was an error in Figs. 8, 9, 10 and 11. During typesetting the Figs. 8, 9, 10 and 11 have been incorrectly swapped. In this "publisher correction" the correct and the incorrect figures are published. The original publication has been updated. BioMed central apologizes to the authors and readers for any inconvenience caused.

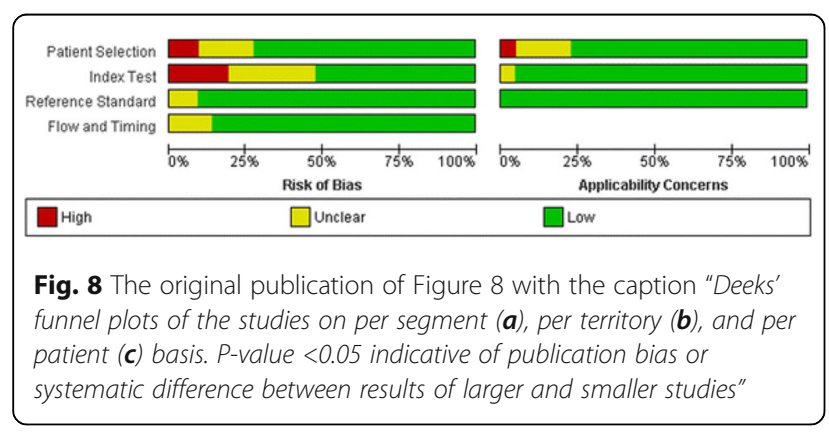

Received: 27 November 2017 Accepted: 29 November 2017

Published online: 04 January 2018

\section{Reference}

1. van Dijk, R., van Assen, M., Vliegenthart, R. et al. J Cardiovasc Magn Reson

(2017) 19: 92. https://doi.org/10.1186/s12968-017-0393-z

\footnotetext{
*Correspondence: info@biomedcentral.com 

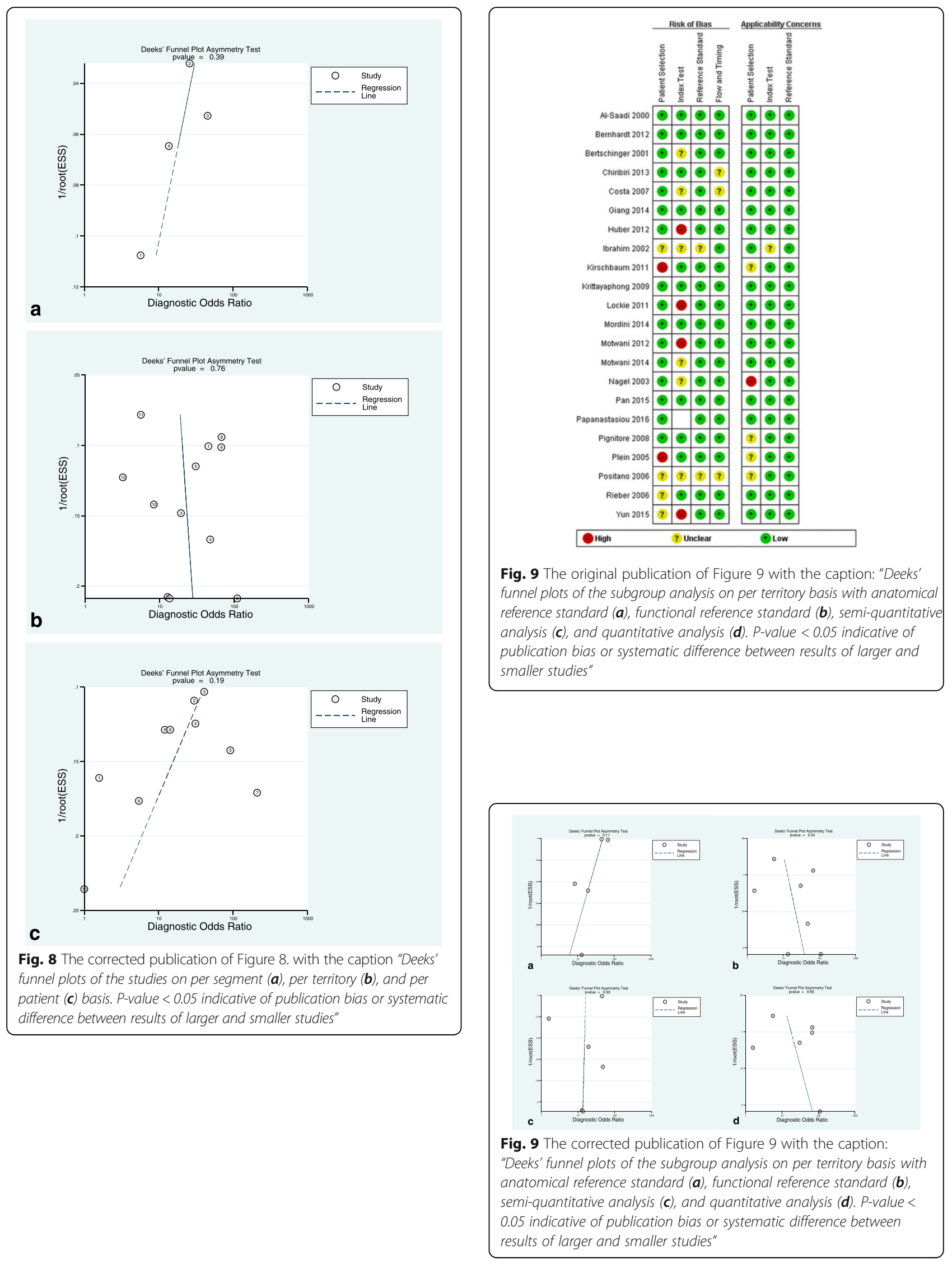

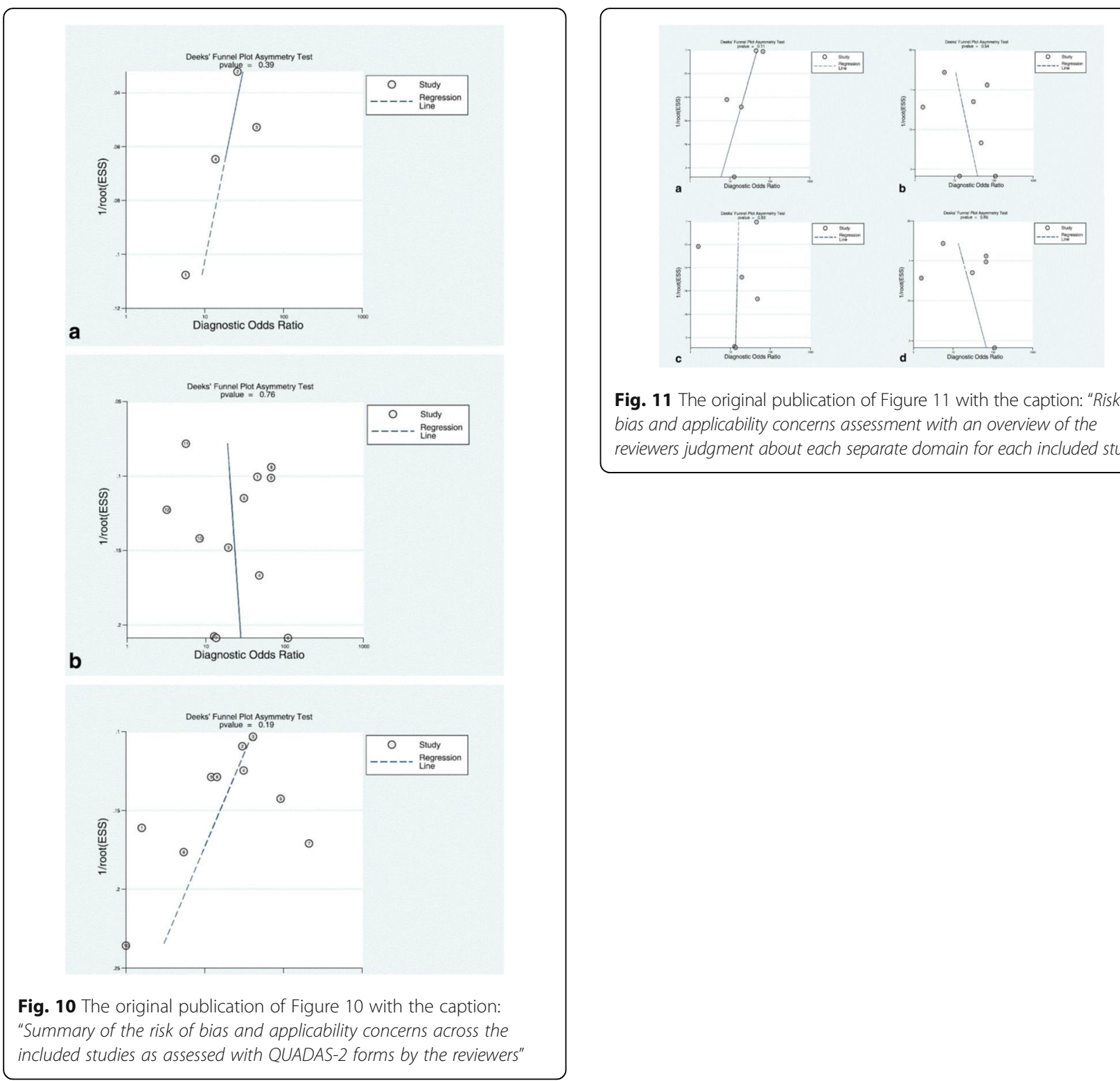

Fig. 11 The original publication of Figure 11 with the caption: "Risk of bias and applicability concerns assessment with an overview of the reviewers judgment about each separate domain for each included study"

Fig. 10 The original publication of Figure 10 with the caption: "Summary of the risk of bias and applicability concerns across the

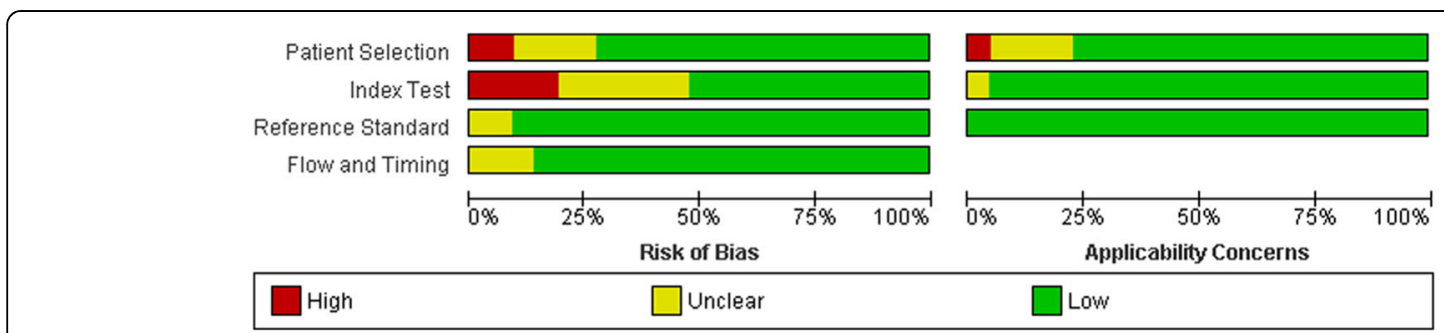

Fig. 10 The corrected publication of Figure 10 with the caption: "Summary of the risk of bias and applicability concerns across the included studies as assessed with QUADAS-2 forms by the reviewers" 
Fig. 11 The corrected publication of Figure 11 with the caption: "Risk of bias and applicability concerns assessment with an overview of the reviewers judgment abeout each separate domain for each included study" 